\title{
ANALISIS SISTEM KERJA INTERNAL KANTOR PELAYANAN PERBENDAHARAAN NEGARA (KPPN) RANTAUPRAPAT
}

\author{
Novrihan Leily Nasution \\ Prodi Manajemen Fakultas Ekonomi Universitas Al Washliyah Labuhanbatu
}

\begin{abstract}
ABSTRAK
Penelitian ini bertujuan untuk menganalisis Sistem Kerja Internal Kantor Pelayanan Perbendaharaan Negara (KPPN) Rantauprapat. Metode yang digunakan dalam penelitian ini adalah metode analisis deskriptif. Sedangkan variabel penelitian adalah sistem kerja internal.

Berdasarkan hasil penelitian ini dapat disimpulkan bahwa Sistem Kerja Internal Kantor Pelayanan Perbendaharaan Negara Rantauprapat yaitu telah menggunakan aplikasi dalam menyelesaikan pekerjaan seperti sistem informasi Gaji Pegawai Pusat (GPP) untuk mengelola gaji dan tunjangan yang secara berkala dilakukan pemutakhiran aplikasi setiap ada informasi pembaruan di KPPN Rantauprapat. Dalam pencairan anggaran belanja negara Kantor Pelayanan Perbendaharaan Negara (KPPN) melakukan penelitian dan pengujian atas SPM yang disampaikan oleh PPSPM. SPM yang diajukan ke KPPN digunakan sebagai dasara penerbitan SP2D, antara lain: 1). SPM LS Belanja Pegawai, 2). SPM UP/TUP, 3). Retur Surat Perintah Pencairan Dana (SP2D), 4). Pembukaan Rekening Pemerintah, 5). Surat Keterangan Penghentian Pembayaran (SKPP).
\end{abstract}

Kata Kunci: Sistem Kerja Internal, Kantor KPPN Rantauprapat

\section{A. Latar Belakang}

Kantor Pelayanan Perbendaharaan Negara (KPPN) Rantauprapat merupakan kantor vertikal Direktorat Jenderal (Ditjen) Perbendaharaan yang merupakan Eselon 1 dari Kementerian Keuangan. Kantor Pelayanan Perbendaharaan Negara (KPPN) Rantauprapat berada di bawah dan bertanggung jawab langsung kepada Kepala Kantor Wilayah Ditjen Perbendaharaan Provinsi Sumatera Utara.

Peran penting Kantor Pelayanan Perbendaharaan Negara (KPPN) adalah melaksanakan kewenangan perbendaharaan dan Bendahara Umum Negara (BUN), penyaluran pembiayaan atas beban anggaran, serta penatausahaan penerimaan dan pengeluaran anggaran melalui dan dari kas negara berdasarkan peraturan perundang-undangan. 
Sesuai ketentuan dalam Undang-undang Nomor 1 Tahun 2004, Perbendaharaan Negara dimengerti sebagai pengelolaan dan pertanggungjawaban Keuangan Negara, termasuk investasi dan kekayaan yang dipisahkan, yang ditetapkan dalam APBN dan APBD. Aspek pengelolaan dan Pertanggungjawaban Keuangan Negara pada prakteknya memiliki detail yang sangat luas. Sesuai dengan pengertian tersebut, dalam Undang-undang Perbendaharaan Negara diatur kewenangan pejabat perbendaharaan negara, pelaksanaan pendapatan dan belanja negara/daerah,pengelolaan uang negara/daerah, pengelolaan piutang dan utang negara/daerah, penatausahaan dan pertanggungjawaban APBN/APBD, pengendalian intern pemerintah, penyelesaian kerugian negara/daerah, serta pengelolaan keuangan badan layanan umum.

Kantor Pelayanan Perbendaharaan Negara (KPPN) adalah perpanjangan tangan pemerintah sebagai kuasa BUN (Bendahara Umum Negara) diseluruh pelosok Indonesia yang bertugas menyalurkan APBN untuk satuan kerja pemerintah yang ada di wilayahnya. Ruang lingkup wilayah kerja Kantor Pelayanan Perbendaharaan Negara (KPPN) Rantauprapat meliputi Kabupaten Labuhanbatu Induk, Labuhanbatu Utara, dan Labuhanbatu Selatan.

Berperan sebagai Kuasa Bendahara Umum Negara di daerah tentu membuat tugas dan fungsi KPPN Rantauprapat sendiri menjadi sangat strategis. Kantor Pelayanan Perbendaharaan Negara (KPPN) Rantauprapat terdapat 4 seksi yaitu Sub Bagian Umum, Seksi Pencairan Dana dan Manajemen Satker (PDMS), Seksi Bank, Seksi Verifikasi Akuntansi dan Kepatuhan Internal (VERA \& KI).

Kantor Pelayanan Perbendaharaan Negara (KPPN) sebagai instansi vertikal Direktorat Jenderal Perbendaharaan juga menjadi pelaku aktif dalam perubahan sistem dan prosedur yang dinamis. Konsekuensi perubahan itu akan bermuara pada kondisi dimana akan adanya kebijakan dan peraturan beragam yang menjadi dasar pelaksanaan tugas dan fungsi di setiap Kantor Pelayanan Perbendaharaan Negara. 
Terkait dengan pelaksanaan tugas dan fungsi seksi-seksi pada Kantor Pelayanan Perbendaharaan Negara (KPPN) Rantauprapat maka penulis tertarik untuk melakukan penelitian "Sistem Kerja Internal Kantor Pelayanan Perbendaharaan Negara (KPPN) Rantauprapat.

\section{A. Permasalahan}

Sistem kerja internal sangat dibutuhkan di setiap instansi/perusahaan karena pada dasarnya pengendalian sistem kerja internal akan mempengaruhi dalam mencapai tujuan sebuah instansi/perusahaan. Dengan sistem kerja yang baik maka instansi/perusahaan dapat berjalan dengan lancar. Sebagai salah satu unit Vertikal Direktorat Jenderal Perbendaharaan yang memiliki fungsi strategis dalam proses meyalurkan APBN maka dalam hal ini penulis akan menganalisis sistem kerja internal di Kantor Pelayanan Perbendaharaan Negara (KPPN) Rantauprapat.

\section{B. Kajian Teori}

Istilah sistem merupakan istilah dari bahasa yunani "system" yang artinya adalah himpunan bagian atau unsure yang saling berhubungan secara teratur untuk mencapai tujuan bersama.

Menurut Irawan, 2009 melalui tulisannya, Sistem kerja adalah serangkaian dari beberapa pekerjaan yang berbeda kemudian dipadukan untuk menghasilkan suatu benda atau jasa yang menghasilkan pelanggan atau keuntungan perusahaan/organisasi. Sistem kerja melibatkan banyak faktor manusia dan adanya keterkaitan pola kerja manusia dengan alat atau mesin, faktor-faktor yang dikombinasikan antara manusia dan alat tersebut suatu prosedur atau tahapan kerja yang sudah tetap dan didokumentasikan sehingga menghasilkan suatu sistem kerja yang konsisten dan dapat menghasilkan hasil kerja yang berkualitas. Contoh di dalam suatu motor, jadi ada bagian yang mengerjakan, masang mesin, masang roda, masang bodinya, masang lampu-lampu dll, terus disatukan dan jadilah suatu produk.

Sistem menurut para ahli : 
L. James Harvey,Sistem adalah prosedur logis dan rasional untuk merancang suatu rangkaian komponen yang berhubungan satu dengan yang lainnya dengan maksud untuk berfungsi sebagai suatu kesatuan dalam usaha mencapai suatu tujuan yang telah ditentukan.

John Mc. Manama, Sistem adalah sebuah struktur konseptual yang tersusun dari fungsi-fungsi yang saling berhubungan yang bekerja sebagai suatu kesatuan organik untuk mencapai suatu hasil yang diinginkan secara efektif dan efisien.

C.W. Churchman, Sistem adalah seperangkat bagian-bagian yang dikoordinasikan untuk melaksanakan seperangkat tujuan.

J.C. Higgins, Sistem adalah seperangkat bagian-bagian yang saling berhubungan.

Edgar F Huse dan James L. Bowdict, Sistem adalah suatu seri atau rangkaian bagian-bagian yang saling berhubungan dan bergantung sedemikian rupa sehingga interaksi dan saling pengaruh dari satu bagian akan mempengaruhi keseluruhan.

Syarat-syarat sistem :

1. Sistem harus dibentuk untuk menyelesaikan tujuan

2. Elemen sistem harus mempunyai rencana yang ditetapkan

3. Adanya hubungan diantara elemen sistem

4. Unsur dasar dari proses (arus informasi, energy dan material) lebih penting dari elemen system

5. Tujuan organisasi lebih penting dari pada tujuan elemen

Menurut Wahyu, 2011 melalui tulisannya :

\section{Pengertian Tata Kerja, Prosedur Kerja, Sistem Kerja dan Contohnya}

a. Tata kerja

Tata kerja merupakan cara pekerjaan dengan benar dan berhasil guna atau bias mencapai tingkat efisien yang maksimal. 
b. Prosedur

Prosedur merupakan tahapan dalam tata kerja yang harus dilalui suatu pekerjaan baik mengenai dari mana asalnya dan mau menuju mana, kapan pekerjaan tersebut harus diselesaikan maupun alat apa yang harus digunakan agar pekerjaan tersebut dapat diselesaikan.

\section{c. Sistem}

Sistem merupakan susunan antara tata kerja dengan prosedur yang menjadi satu sehingga membentuk suatu pola tertentu dalam menyelesaikan suatu pekerjaan. Contohnya : Stabilitas : maksudnya bahwa sistem, tata, dan prosedur kerja itu harus mengandung unsur tetap sehingga menjamin kelancaran dan kemantapan kerja.

Fleksibilitas : artinya bahwa dalam pelaksanaanya tidak kaku tetapi harus luwes yaitu masih memungkinkan diadakannya saling pergantian tugas.

Contoh : Salah seoerang tidak masuk atau kebetulan salah satu mesin macet, maka pekerjaan harus tetap dapat terlaksana dan diselesaikan.

2. Analisa Jabatan, Job Description dan Job Spesification

a. Analisa Jabatan

Analisa jabatan adalah suatu proses pemahaman yang mendalam tentang isi dan karakteristik suatu jabatan. Uraian jabatan ( job description) pada prinsipnya merupakan produk utama dari studi analisa jabatan.

b. Job Description dan Job Requirement / Job Specification Persyaratan jabatan merupakan hasil sampingan dari studi analisa jabatan dan terpisah dari uraian jabatan sebagai produk utama analisa jabatan. Isi dari jabatan uraian jabatan merupakan informasi tentang suatu jabatan yang membedakannya dengan jabatan lainnya. Ciri khas uraian jabatan adalah 
menggambarkan apa, mengapa, bagiamana, dan kapan / dimana jabatan tersebut ditempatkan dan dilaksanakan. Sedangkan Job Requirment / Job Specification merupakan persyaratan utama dari seseorang pemangku jabatan (job holder) untuk menduduki jabatan tersebut. Sedangkan isi dari persyaratan jabatan biasanya terdiri dari Pendidikan Formal,Pengalaman Kerja, pelatihan, Persyaratan Fisik, Persyaratan Psikologis, kemampuan khusus.

Menurut Indra Rukmananda, 2014 melalui tulisannya :

Perancangan Sistem Kerja adalah suatu ilmu yang mempelajari prinsipprinsip dan teknik-teknik untuk mendapatkan suatu rancangan sistem kerja yang terbaik. Ilmu ini merupakan salah satu ilmu didalam disiplin teknik industri, bahkan dilihat dari sejarahnya, Perancangan Sistem Kerja merupakan cikal bakal disiplin ini.

Dalam penerapannya, Perancangan Sistem Kerja akan berinteraksi dengan berbagai ilmu lain didalam disiplin teknik industri untuk secara bersamaan mencapai keadaan optimal dari suatu system produksi dalam arti kata yang luas, yaitu sistem yang terdiri dari komponen-komponen manusia, bahan, mesin, peralatan, dan uang.

Sebagai suatu ilmu, Perancangan Sistem Kerja mempunyai kerangka sendiri dengan bagian-bagiannya yang secara bersam-sama terpadu untuk mencapai tujuan diatas.

Perancangan Sistem Kerja ini dikembangkan oleh F.W. Taylor dan F.B. Gilbreth. Berdasarkan penelitian dari F.W. Taylor dan F.B. Gilbreth, walaupun penelitian tersebut tidak dilakukan secara bersama-sama, yang dikemudian hari dikenal sebagai suatu kesatuan dan dikenal sebagai Perancangan Kerja atau Methods Engineering. Perancangan ini dilakukan dengan memperhatikan aspekaspek teknologi, psikologis, dan sosiologis kerja sehingga diperoleh sistem kerja yang lebih sesuai dengan kemampuan serta keterbatasan manusia.

Pengembangan teknik tata cara kerja berdasarkan teori F.W. Taylor dan F.B. Gilbreth.

1. F.W. Taylor (1981)

a. Memperhatikan para pekerja dan menilai mereka tidak berprestasi maksimal.

b. Taylor menggunakan jam henti (stopwatch) untuk melakukan pengukuan waktunya.

c. Pengukuran waktu ini dikembangkan terus sampai dikenal istilah waktu baku/standar untuk suatu pekerjaan.

d. Penentuan aktu bagi suatu pekerjaan sangat penting bagi sistem produksi: upah perangsang, penjadwalan kerja dan mesin, pengaturan tata letak pabrik.

e. 
2. Frank B. Gilbreth

a. Melakukan penelitian terhadap gerakan-gerakan kerja dan membaginya menjadi sejumlah elemen-elemen gerakan.

b. Misalnya gerakan tangan mengambil sebuah gelas diurai menjadi elemen-elemen menjangkau, memegang, dan mengangkat.

c. Bersama istrinya, Lilian yang juga seorang psikolog, keduanya mengembangkan serangkaian prinsip Perancangan Sistem Kerja yang dikenal dengan Ekonomi Gerakan.

d. Tujuannya untuk menghasilkan suatu sistem kerja yang terancang baik, sehingga memudahkan dan menyamankan gerakan-gerakan kerja untuk menghindari atau melambatkan datangnya kelelahan (fatique).

Pada proses produksi, perancangan stasiun kerja dan metode kerja bukan hal mudah. Kesalahan dalam perancangan maupun metode kerja akan berdampak buruk pada proses secara keseluruhan. Evaluasi perancangan harus dilakukan secara terus menerus untuk mendapatkan metode terbaik.

Oleh karena itu, perancangan sistem kerja merupakan bagian yang sangat penting dan harus diperhatikan untuk mencapai tujuan dalam melaksanakan kegiatan perusahaan.

Perancangan Sistem Kerja

Untuk mencari sistem kerja terbaik, kita harus menganalisa masalah-masalah yang mungkin muncul. Langkah-langkah penyelesaian masalah tersebut adalah sebagai berikut:

1. Mendefinisikan masalah

2. Menganalisa masalah

3. Mencari alternative solusi

4. Mengevaluasi alternative solusi

5. Mengimplementasikan solusi

Penganalisaan Sistem Kerja

Komponen pembentuk sistem kerja antara lain :

1. Manusia

2. Bahan

3. Mesin

4. Lingkungan Kerja

5. Ergonomi

Handoko, 2012 : Pekerjaan-pekerjaan dapat diibaratkan sebagai jembatan penghubung antara karyawan dan organisasi. Lowongan-lowongan pekerjaan merupakan penyebab timbulnya kebutuhan organisasi akan sumber daya manusia. 
Bila departemen personalia hendak membantu organisasi untuk memperoleh dan memelihara satuan kerja yang diinginkan, maka para spesialis personalia harus mempunyai pemahaman tentang desain pekerjaan. Desain pekerjaan adalah fungsi penetapan kegiatan-kegiatan kerja seorang individu atau kelompok karyawan secara organisasional.

Husni, 2006 : Aspek hukum ketenagakerjaan dalam hubungan kerja (During Employment) yaitu :

1. Perjanjian kerja sebagai dasar lahirnya hubungan kerja

2. Perlindungan norma kerja

3. Pengawasan perburuhan

4. Perselisihan perburuhan atau hubungan industrial

5. Keselamatan kesehatan kerja

6. Perlindungan upah

7. Jamsostek

8. Mogok kerja dan penutupan perusahaan

\section{Hasil dan Pembahasan}

Berdasarkan hasil pengamatan dan analisa terhadap sistem kerja internal di Kantor Pelayanan Perbendaharaan Negara (KPPN) Rantauprapat yaitu telah menggunakan aplikasi dalam menyelesaikan pekerjaan seperti sistem informasi Gaji Pegawai Pusat (GPP) untuk mengelola gaji dan tunjangan yang secara berkala dilakukan pemutakhiran aplikasi setiap ada informasi pembaruan di KPPN Rantauprapat.

Dalam pencairan anggaran belanja negara Kantor Pelayanan Perbendaharaan Negara (KPPN) melakukan penelitian dan pengujian atas SPM yang disampaikan oleh PPSPM. SPM yang diajukan ke KPPN digunakan sebagai dasar penerbitan SP2D.

\section{SPM LS Belanja Pegawai}

Surat Perintah Membayar Langsung (SPM-LS) adalah dokumen yang diterbitkan oleh PPSPM (Pejabat Penandatanganan Surat Perintah Membayar) untuk mencairkan dana yang bersumber dari DIPA dalam rangka pembayaran tagihan kepada penerima hak/Bendahara Pengeluaran. PPSPM bertanggungjawab atas kebenaran, kelengkapan, 
dan keabsahan administrasi terhadap dokumen hak tagih pembayaran yang menjadi dasar penerbitan SPM dan akibat yang timbul dari pengujian yang dilakukannya serta ketetapan jangka waktu penerbita dan penyampaian SPM kepada KPPN.

\section{Kelengkapan SPM}

a. SPM-LS Belanja Pegawai Gaji dalam rangkap 2 (dua); Kode Jenis SPM: 01, 02, 03

b. ADK SPM yang telah diinjeksi PIN oleh PPSPM;

c. ADK Perubahan

d. ADK Gaji

e. Daftar Perubahan Gaji

f. Surat Setoran Pajak (SSP) dan/atau bukti setor lainnya.

Contoh uraian SPM : Pembayaran (gaji induk/gaji bulan- 13/gaji susulan/terusan) kekurangan gaji/UDW/UDT/posekot gaji bulan untuk pegawai/ jiwa

SPM LS Belanja Pegawai Gaji (Non Aplikasi GPP/BPP)

\section{Kelengkapan SPM}

a. SPM-LS Belanja Pegawai Gaji dalam rangkap 2 (dua); Kode Jenis SPM: 01, 02, 03

b. ADK SPM yang telah diinjeksi PIN oleh PPSPM;

c. Daftar Gaji Induk lengkap (untuk non gaji induk berupa Daftar Kekurangan Gaji, Daftar Gaji Susulan, Posekot Gaji dsb);

d. Dokumen Pendukung Perubahan Gaji (SK KP, SK KGB,KP4 dsb);

e. Surat Setoran Pajak (SSP) dan/atau bukti setor lainnya.

\section{Contoh uraian SPM}

Pembayaran (gaji idnuk/gaji susulan/kekurangan gaji/posekot gaji dsb) bulan untuk pegawai/ jiwa

\section{SPM UP/TUP}

Batas Pemberian Uang Persediaan 
1. Rp50.000.000,- (lima puluh juta rupiah) untuk pagu jenis belanja yang bisa dibayarkan melalui UP sampai dengan Rp900.000.000 (sembilan ratus juta rupiah);

2. Rp100.000.000 (seratus juta rupiah) untuk pagu jenis belanja yang bisa dibayarkan melalui UP di atas Rp900.000.000 (sembilan ratus juta rupiah) sampai dengan Rp2.400.000.000 (dua miliar empat ratus juta rupiah);

3. Rp200.000.000 (dua ratus juta rupiah) untuk pagu jenis belanja yang bisa dibayarkan melalui UP di atas Rp2.400.000.000 (dua miliar empat ratus juta rupiah) sampai dengan Rp6.000.000.000 (enam miliar rupiah); atau

4. Rp500.000.000 (lima ratus juta rupiah) untuk pagu jenis belanja yang bisa dibayarkan melalui UP di atas Rp6.000.000.000 (enam miliar rupiah).

Pembayaran dengan Uang Persediaan dan Tambahan Uang Persediaan

1. Pembayaran dengan UP yang dapat dilakukan oleh Bendahara Pengeluaran/BPP kepada 1 (satu) penerima/ penyedia barang/jasa paling banyak sebesar Rp.50.000.000,- (lima puluh juta rupiah) kecuali untuk pembayaran honorarium dan perjalanan dinas.

2. UP dapat diberikan untuk pengeluaran-pengeluaran:Pengajuan SPM GUP (Penggantian UP) dilakukan apabila UP telah dipergunakan paling sedikit 50\% (lima puluh persen).

a. Belanja Barang;

b. Belanja Modal; dan

c. Belanja Lain-lain.

3. Dalam hal 2 (dua) bulan sejak SP2D-UP diterbitkan belum dilakukan pengajuan penggantian UP, kepala KPPN menyampaikan surat pemberitahuan kepada KPA,

4. Dalam hal setelah 1 (satu) bulan sejak disampaikan surat pemberitahuan sebagaimana dimaksud, belum dilakukan pengajuan penggantian UP, Kepala KPPN memotong UP sebesar $25 \%$ (dua puluh lima persen).

\section{Kelengkapan SPM :}

1. SPM UP / TUP dalam rangkap 2 (dua);

2. ADK SPM yang telah diinjeksi PIN oleh PPSPM;

3. Surat Pernyataan dari KPA dengan format sesuai lampiran XIV PMK 190/PMK.05/2012 (untuk SPM UP); Surat persetujuan pemberian TUP dari Kepala KPPN (untuk SPM-TUP). 
Contoh uraian SPM

a. Penyediaan Uang Persediaan (RM/ PLN/ PNBP) Satker Tahun 2013

b. Penyediaan Tambahan Uang Persediaan (RM/ PLN/ PNBP) Satker Tahun 2013

\section{Retur Surat Perintah Pencairan Dana (SP2D)}

Retur SP2D adalah penolakan/pengembalian atas pemindahbukuan dan/atau transfer pencairan APBN dari Bank/Kantor Pos Penerima kepada Bank/Kantor Pos Pengirim.

Dasar Hukum: Peraturan Direktur Jenderal Perbendaharaan Nomor PER-30/PB/2014 tentang Mekanisme Penyelesaian dan Penatausahaan Retur Surat Perintah Pencairan Dana Dalam Rangka Implementasi Sistem Perbendaharaan dan Anggaran Negara.

Alasan terjadi retur SP2D antara lain :

a. Kesalahan/perbedaan nama/nomor rekening SP2D

b. Kesalahan penulisan nama bank penerima

c. Rekening tidak aktif/tutup/pasif

Prinsip dasar penatausahaan dana retur :

a. Retur yang diterima selama tahun berjalan (belum disetor ke kas negara) dapat dibayarkan kembali dengan penerbitan surat ralat rekening SP2D.

b. Kesalahan retur yang telah disetorkan ke kas negara dapat dibayarkan kembali melalui penerbitan SPM-PP/SP2D oleh KPPN setelah ada pengajuan surat permohonan pembayaran kembali dari KPA/satuan kerja.

Surat ralat/perbaikan dan permohonan perbaikan pembayaran kembali disampaikan kepada KPPN dilampiri :

a. Surat Pernyataan Tanggung Jawab Mutlak (SPTJM).

b. Fotocopy buku tabungan/rekening giro yang telah dilegalisir bank/kantor pos penerima. 
c. Surat pernyataan dari bank/kantor pos penerima bahwa rekening berkenaan masih aktif minimal sampai dengan 1 (satu) bulan setelah tanggal surat ralat dari KPA/satker.

d. Perbaikan resume kontrak dalam hal ralat mengakibatkan perubahan data rekening dalam kontrak/resume kontrak.

e. ADK SPM, Copy SPM dan SP2D sebelum koreksi serta SPM setelah koreksi dalam hal ralat mengakibatkan perubahan data pada SPM dan SP2D

\section{Pembukaan Rekening Pemerintah}

1. Persetujuan yang dapat diberikan Kepala KPPN selaku Kuasa Bendahara Umum Negara di daerah adalah pembukaan rekening bendahara pengeluaran kepada Kuasa Pengguna anggaran dengan Prinsip : 1 (satu) Satuan Kerja, 1 (satu) DIPA, 1 (satu) Bendahara, dan 1 (satu) rekening. Sedangkan untuk rekening bendahara penerimaan, pemberian izin pembukaaan rekening menggunakan prinsip yang sama dengan rekening bendahara pengeluaran dengan memperhatikan Tusi Satuan kerja yang bersangkutan.

2. Kepala Kantor / Satuan Kerja selaku Kuasa Pengguna Anggaran mengajukan tujuan pembukaan rekening sesuai prinsip diatas, dengan dilampiri:

a. Foto copy dokumen pelaksanan anggaran;

b. Surat Pernyataan tentang Penggunaan Rekening.

c. Rekening Penerimaan,

Rekening Pengeluaran yang dibuka sebelum berlakunya Peraturan menteri Keuagan No. 57/PMK.05/2007 harus dimintakan persetujuan kepada Kepala KPPN sebagai Kuasa BUN di daerah dengan menggunakan prinsip diatas:

d. Kepala Kantor / Satuan Kerja yang telah mendapatkan persetujuan lebih dari satu rekening untuk rekening penerimaan dan/atau rekening pengeluaran agara menutup yang lebih dari satu tersebut.

e. KPPN sebagai Kuasa BUN berwenang melakukan Pembekuan Sementara Rekening dalam hal:

1. Kepala Kantor / Satuan Kerja membuka rekening tanpa persetujuan Kuasa BUN. 
2. Kepala kantor/ Satuan Kerja tidak melaporkan pembukaan rekening yang dilakukan kepada Kuasa BUN paling lambat 5 (lima) hari kerja sejak tanggal pembukaan rekening.

3. Kepala Kantor / Satuan Kerja tidak mengajukan permohonan persetujuan kepada Kuasa BUN atas

4. Rekening yang dibuka sebelum berlakunya PMK No. 57/PMK.05/2007 tentang Pengelolaan Rekening Milik Kementrian Negara / lembaga / Kantor / Satuan Kerja;

5. Rekening yang tidak atau tidak lagi digunakan sesuai dengan tujuan pembukaannya harus ditutup oleh Kepala Kantor / Satuan Kerja dan saldonya dipindahkan ke Rekening Kas Negara pada Bank Indonesia.

6. KPPN sebagai Kuasa BUN di Daerah berwenang menutup Rekening dan memindahbukukan saldonya ke Rekening Kas Umum Negara dalam hal :

a. Rekening yang tidak atau tidak lagi digunakan sesuai dengan tujuan pembukaannya tidak ditutup oleh Kepala Kantor / Satuan Kerja;

b. Kepala Kantor / Satuan Kerja dalam waktu 30 (tiga puluh) hari kerjsa setelah tanggal pembekuan sementara, tidak melaksanakan tindak lanjut terhadap Rekening yang dibekukan sementara tersebut.

\section{Surat Keterangan Penghentian Pembayaran (SKPP)}

Surat Keterangan Penghentian Pembayaran (SKPP) adalah surat keterangan tentang terhitung mulai bulan dihentikan pembayaran yang dibuat/dikeluarkan oleh Pengguna Anggaran/KPA berdasarkan surat keputusan yang diterbitkan oleh Kementerian Negara/Lembaga atau satker dan disahkan oleh KPPN setempat.

1. SKPP pegawai pindah diterbitkan rangkap 4 (empat) dengan penjelasan :

a. lembar I untuk pegawai yang bersangkutan untuk dilampirkan pada saat pengajuan gaji pertama kali ditempat yang baru;

b. lembar II untuk satuan kerja yang baru, dilampiri dosir kepegawaian dan ADK pegawai pindah;

c. lembar III untuk KPPN asal sebagai pertinggal;

d. lembar IV untuk pertinggal satuan kerja yang bersangkutan. 
SKPP diatas dilampiri Surat Keputusan (SK) Pindah

2. SKPP pegawai pensiun diterbitkan rangkap 5 (lima) dengan penjelasan:

a. lembar I \& II kedua untuk kepada PT. Taspen (Persero)/PT. ASABRI (Persero);

b. lembar III untuk kepada pegawai yang bersangkutan;

c. lembar IV untuk KPPN sebagai Pertinggal;

d. lembar V untuk satuan kerja bersangkutan.

SKPP diatas dilampiri Surat Keputusan (SK) Pensiun dari Badan Kepegawaian Negara (BKN)

SKPP dikirim oleh Satuan kerja asal sesuai peruntukannya sebagaimana diatur pada angka 1 dan 2 setelah diberi keterangan oleh Kepala Seksi Pencairan Dana pada KPPN asal bahwa data pegawai pindah/pensiun telah dinonaktifkan dari database pegawai satuan kerja tersebut pada KPPN asal.

Sistem kerja internal pegawai kantor pelayanan perbendaharaan Negara (KPPN) Rantauprapat menunjukan bahwa setiappegawai melakukan pekerjaan dengan kedisiplinan yang tinggi dalam melakukan pekerjaan untuk memperoleh hasil yang optimal.Dengan sistem kerja internal yang baik pegawai akan mampu bekerja secara efektif dan efisien.

\section{Kesimpulan dan Saran}

\section{Kesimpulan}

Sistem kerja internal di kantor pelayanan perbendaharaan Negara (KPPN) Rantauprapat dalam penyaluran dana APBN di Rantauprapat dalam kategori cukup profesional karena pegawai KPPN Rantauprapat bekerja sesuai dengan SOP yang berlaku serta profesionalisme dan etos kerja yang diterapkan oleh semua pegawai KPPN Rantauprapat.

2. Saran

Saran untuk Kantor Pelayanan Perbendaharan Negara (KPPN) Rantauprapat adalah agar lebih mensosialisasikan KPPN Rantauprapat di kalangan masyarakat 
khususnya para pelajar agar lebih mengerti dan memahami tentang fungsi dan tanggung jawab KPPN Rantauprapat.

\section{E. Daftar Bacaan}

Handoko, 2012, Manajemen Personalia dan Sumber Daya Manusia, Penerbit: BPFE-YOGYAKARTA, Edisi Kedua, Yogyakarta

Hendrayana, 2014, http://indrarukmanandahendrayana.blogspot.com/2014/05/perancangan-sistemkerja.html

Husni, 2006, Hukum Ketenagakerjaan Indonesia, Penerbit: PT RajagrafindoPersada, Edisi Revisi, Jakarta

Irawan, 2009, http://iwanirawanumc2009.blogspot.com/2010/10/definisi-sistemkerja.html

Wahyu, 2011, https://wahyu410.wordpress.com/2011/05/15/pengertian-tatakerjaprosedur-kerja-dan-sistem-kerja-juga-analisis-jabatan-job-description-and-jobspecification/ 